\title{
A incompreensão dos profissionais de secretariado sobre o que são os gêneros textuais/discursivos: um estudo de caso
}

The incomprehension of secretarial professionals about what textual/discursive genres are: a case study

\author{
Eduardo César Pereira Souza ${ }^{1}$ (D) \\ ${ }^{1}$ Universidade Federal do Amapá (Unifap), Brasil, Mestre em Linguística (Unicsul), e-mail: edwardsouza3@gmail.com
}

\section{RESUMO}

No âmbito da atuação do profissional de secretariado parece existir uma diversidade de gêneros textuais/discursivos de língua estrangeira. Assim sendo, este trabalho objetiva conhecer a compreensão desses trabalhadores sobre os gêneros textuais/discursivos e busca responder à seguinte questãoproblema: qual a compreensão dos profissionais secretariais sobre os gêneros textuais/discursivos? Este estudo se justifica à medida que se nota a importância de entender o funcionamento dos gêneros textuais/discursivos nas mais diferentes profissões e sua influência nas práticas sociais que pode representar uma possibilidade de ressignificar o lugar da ocupação e de sua atuação cotidiana. No que diz respeito ao recorte teórico, recorre-se a autores como Miller (1984), Bazerman (2011), Marcuschi (2008, 2011), Bezerra (2017) dentre outros. A metodologia é de natureza exploratória, qualitativa, bibliográfica e de campo. Com os principais achados foi possível concluir que não há clareza teórica por parte dos secretários participantes da pesquisa sobre os estudos dos gêneros textuais/discursivos nessa prática profissional, fruto, inclusive, da falta de conhecimento de alguns deles sobre a conceituação de gêneros textuais/discursivos.

Palavras-chave: Gêneros textuais/discursivos. Língua estrangeira. Secretariado.

\begin{abstract}
In the scope of the secretarial work, there seems to be a diversity of textual/discursive genres of foreign language. Therefore, this work aims at knowing the understanding of these workers about the textual/discursive genres and seeks to answer the following problem question: what is the understanding of the secretarial professionals about the textual/discursive genres? This study is justified as we notice the importance of understanding the functioning of the textual/discursive genres in the most different professions and their influence on social practices, which may represent a possibility of re-signifying the place of occupation and its daily performance. As far as the theoretical approach is concerned, authors such as Miller (1984), Bazerman (2011), Marcuschi (2008, 2011), Bezerra (2017), among others, are used. The methodology is exploratory, qualitative, bibliographic and field. With the main findings it was possible to conclude that there is no theoretical clarity on the part of the secretaries participating in the research about the studies of textual/discursive genres in this professional practice, as a result of the lack of knowledge of some of them about the conceptualization of textual/discursive genres.
\end{abstract}

Keywords: Textual/discursive genres. Foreign language. Secretariat. 


\section{INTRODUÇÃO}

A quantidade de estudos e pesquisas sobre as contribuições dos gêneros textuais/discursivos (de língua materna e estrangeiras) para a área de secretariado ainda é deficitária. Esse fato parece ficar comprovado quando se visualiza as listas de trabalhos aprovados para apresentação oral ou pôster em eventos como: VI Encontro Nacional Acadêmico de Secretariado Executivo (ENASEC 2019) e XII Encontro Nacional dos Estudantes de Secretariado (ENESEC 2020), nos dois, apenas quatro artigos sobre a temática.

Ainda que pareça ser um assunto novo, o estudo dos gêneros textuais/discursivos já era explorado nos Estados Unidos por autores como Swales e Miller na década de 1980. Entretanto, no Brasil, ficou-se atribuído à Motta-Roth (1995), Araújo (1996) e Biasi-Rodrigues (1998) o pioneirismo das primeiras investigações nessa área a partir de suas pesquisas de doutorado. De mais a mais, aqui no contexto brasileiro, o termo gêneros só veio a se popularizar, de fato, com a chegada dos Parâmetros Curriculares Nacionais (PCN) para o ensino de Língua Portuguesa (LP) no nível fundamental, em 1998 (BEZERRA, 2017).

Considera-se que "seria gritante ingenuidade histórica imaginar que foi nos últimos decênios do século XX que se descobriu e iniciou o estudo dos gêneros textuais" (MARCUSCHI, 2008, p. 147). Igualmente, também seria credulidade pensar que o estudo dos gêneros textuais/discursivos nas perspectivas contemporâneas se deve unicamente à difusão dos PCN (BEZERRA, 2017). Como diria Marcuschi (2008, p. 147), “o estudo dos gêneros não é novo, mas está na moda".

A motivação para esta investigação aparece quando se constatam as lacunas existentes no que se relaciona ao ensino e aprendizagem de línguas estrangeiras para o secretariado, já que há carência de materiais didáticos e estudos produzidos pelos próprios secretáriospesquisadores (SOUZA, 2015, 2018). Como justificativa, podemos citar a inexistência de programas de pós-graduação stricto sensu específicos da área (MARTINS et al., 2011) ou ainda o fato de que somente a partir da consulta pública realizada pela Secretaria de Educação Superior (SESu), no ano de 2009, foi que os professores e pesquisadores atentaram para o incipiente número de pesquisas científicas e começaram a dedicar-se a buscar por um conhecimento científico efetivamente reconhecido pela academia (MARTINS et al., 2017).

Revista Expectativa, Toledo/PR, v.20, n. 2, p. 67-89, abr./jun., 2021. 
Esta pesquisa se justifica à medida que se julga importante entender a compreensão dos profissionais de secretariado sobre os gêneros textuais/discursivos de língua estrangeira, uma vez que isso pode influenciar nas práticas sociais desses trabalhadores (e muitas vezes o faz, principalmente no transcurso da formação do profissional) uma possibilidade de ressignificar, remodelar e/ou reconstruir o lugar da profissão e de sua prática cotidiana.

Assim sendo, este trabalho tem por objetivo geral conhecer a compreensão dos profissionais de secretariado sobre os gêneros textuais/discursivos. Para tanto, elencam-se os objetivos específicos: a) descobrir se os profissionais da área sabem o que são os gêneros textuais/discursivos; b) identificar, no que tange aos que conhecem o que são, como eles materializam esse conceito de gênero textual/discursivo; c) verificar se, no trabalho diário como secretário, assessor ou assistente, é demandada atuação com gêneros textuais/discursivos de língua estrangeira; e d) entender quais seriam as contribuições dos gêneros textuais/discursivos de língua estrangeira para a área de secretariado a partir do ponto desses trabalhadores. Desse modo, busca-se responder à seguinte questão-problema: qual a compreensão dos profissionais secretariais sobre os gêneros textuais/discursivos?

Para dar conta do que é proposto neste artigo, estrutura-se o texto da seguinte forma: depois desta introdução, apresentam-se os referenciais teóricos, divididos em dois momentos (o primeiro, trata das questões conceitos de gêneros textuais/discursivos, e o segundo, revisita estudos específicos no campo secretarial sobre a temática em pauta); na sequência, tem-se os aspectos metodológicos traçados para o estudo, a apresentação dos resultados da investigação e sua discussão e, por fim, as considerações finais e referências.

\section{REFERENCIAL TEÓRICO}

\subsection{GÊNEROS TEXTUAIS/DISCURSIVOS: UM CONCEITO INERENTE AO TEXTO E AO DISCURSO}

Neste estudo, faz-se uma opção teórica pela nomenclatura gêneros textuais/discursivos e, desse modo, parece ser contraditório o fato de não escolher um dos polos (gêneros textuais ou gêneros discursivos). No entanto, a utilização dos termos "textual ou discursivo" é apenas uma forma polifônica que os pesquisadores utilizam para se aproximarem ou se afastarem da

Revista Expectativa, Toledo/PR, v.20, n. 2, p. 67-89, abr./jun., 2021. 
perspectiva bakhtiniana. Quer dizer, quando uso "gênero discursivo", estou me aproximando de Bakhtin, quando uso "gênero textual", estou me distanciando dessa corrente. Na verdade, isso nada mais é do que a sinalização de uma filiação teórica específica (ROJO, 2005). Em suma, "o gênero não é discursivo ou textual, mas é simultaneamente indissociável tanto do discurso quanto do texto e seria um equívoco reduzi-lo a qualquer um desses polos" (BEZERRA, 2017, p. 13).

Também no âmbito conceitual da teoria, é comum certos equívocos quando se tenta estabelecer relação entre gênero, texto e discurso. Especificamente, acontecem tais confusões nos seguintes pares: gênero e texto, gênero e suporte, gênero e domínio discursivo, gênero e forma/estrutura e gênero e tipo textual.

De acordo com Bezerra (2017), essas incorreções desembocam em duas subclasses centrais: “[...] confundir gênero com suporte, com forma/estrutura e com tipo textual revela, ao fim e ao cabo, diferentes aspectos da confusão entre gênero e texto; [...]” (BEZERRA, 2017, p. 44). Depois, o desacerto entre gênero e domínio discursivo tem a ver com a sobreposição de certo modo parcial entre os conceitos de gênero e de discurso. Sobre identificar gênero com suporte, o desalinho se dá mais propriamente entre gênero e o texto aportado no referido suporte, e não diz respeito a superfície material em questão, ainda que a nomeação do gênero se realize nela em um processo de certo modo "multimodal". Quanto à diminuição de gênero a um formato ou estrutura textual, isso só é possível se o texto e o gênero forem percebidos como uma coisa só. O gênero é objetivado na forma de um texto pronto ou seria "materializado"? Por fim, na junção de gênero e tipo ou sequência textual, novamente tem-se a identificação do gênero com as formas estruturais e composicionais que determinam o texto e não o gênero (BEZERRA, 2017).

Os gêneros podem ser percebidos como formas verbais do que conhecemos como ação social, estabilizados e recorrentes em textos situados nas diferentes comunidades de práticas e em domínios discursivos específicos (MILLER, 1984). Assim sendo, podemos dizer que eles são "entidades dinâmicas, históricas, sociais, situadas, comunicativas, orientadas para fins específicos, ligadas a determinadas comunidades discursivas, ligadas a domínios discursivos, recorrentes e estabilizadas em formatos mais ou menos claros" (MARCUSCHI, 2008, p. 159).

A forma como se deve conviver com os gêneros textuais/discursivos diz respeito ao trato da língua em seu cotidiano nas mais diversas esferas (MARCUSCHI, 2008). Estudar 
gêneros é enveredar por caminhos que procurem responder às demandas das práticas sociais em determinados contextos. Em outros termos, pode-se afirmar que "os gêneros tipificam muitas coisas além da forma textual. São parte do modo como os seres humanos dão forma às atividades sociais." (BAZERMAN, 2011, p. 32). Isso quer dizer que os "gêneros emergem nos processos sociais em que pessoas tentam compreender umas às outras suficientemente bem para coordenar atividades e compartilhar significados com vistas a seus propósitos práticos" (BAZERMAN, 2011, p. 32). Levando-se em consideração uma ata, por exemplo, sua função prática situa-se no registro oficial das discussões realizadas em um determinado evento comunicativo com vistas a facilitar a eventual consulta por parte de um interessado. Como possível resultado, acredita-se que ela poderia contribuir na agilidade dos processos de tomada de decisão dos gestores organizacionais (SOUZA, 2018).

Paralelamente, deve-se pensar ainda que "nem todos os gêneros têm o mesmo grau de estabilidade e de identificação autoral e muitos deles são menos próprios para a análise de autoria, pois são gêneros formulaicos” (MARCUSCHI, 2011, p. 30). Dessa forma, os gêneros não devem ser percebidos como um protótipo, ou seja, “entidades a serem reproduzidas ou imitadas, seja no ensino ou no dia a dia, pois são de tal ordem que mais parecem paradigmas de heterogeneidade enunciativa" (MARCUSCHI, 2011, p. 31). Em outras palavras, quando se ensina a alguém a atuar por meio do e com gênero, ensina-se um modo de "atuação sociodiscursiva" numa dada cultura e não apenas um simples modo de (re)produção textual (MARCUSCHI, 2011).

Ampliando as discussões sobre os gêneros, Bazerman (2011, p. 59) esclarece que

as formas de escrita são fenômenos históricos - criados, reconhecidos, mobilizados e fortalecidos dentro da mente de cada escritor e leitor em momentos sócio-históricos específicos, mas transmitidos na acumulação de textos. A experiência textual acumulada e socialmente contextualizada aumenta o repertório formal e o comando processual de cada escritor e leitor.

Desse modo, entende-se que o gênero textual/discursivo "não é simplesmente uma categoria linguística definida pelo arranjo estruturado de traços textuais” (BAZERMAN, 2011, p. 60), mas, sim, "uma categoria sociopsicológica que usamos para reconhecer e construir ações tipificadas dentro de situações tipificadas" (BAZERMAN, 2011, p. 60). Os gêneros textuais/discursivos não operam no vácuo, eles estão muito bem situados dentro de circunstâncias de interação do mundo real.

Revista Expectativa, Toledo/PR, v.20, n. 2, p. 67-89, abr./jun., 2021. 
Dito isso, no próximo item, trata-se de revisitar estudos sobre os gêneros textuais/discursivos de língua estrangeira no secretariado.

\subsection{REVISITANDO ESTUDOS SOBRE OS GÊNEROS TEXTUAIS/DISCURSIVOS DE LÍNGUA ESTRANGEIRA NO SECRETARIADO}

Ao realizar buscas em plataformas como SciELO, Scopus, Google Acadêmico, Biblioteca Digital de Teses e Dissertações (BDTD), num recorte temporal dos últimos 10 anos, é possível encontrar alguns estudos e pesquisas sobre os gêneros textuais/discursivos de língua estrangeira, notadamente sobre inglês e espanhol.

Em Lugli (2011), buscou-se apresentar uma análise preliminar de uma unidade didática presente em um livro de espanhol, utilizado no curso de Secretariado Executivo de uma universidade do norte do Paraná. A autora chegou à conclusão de que para falar especificamente das capacidades de linguagem, nas unidades de 1 a 8, em um total de 77 atividades, só em 23 percebeu-se o potencial de desenvolver as capacidades de ação porque elas incitam o aluno a refletir sobre o texto do livro e sobre o texto da internet, relacionando-o com o mundo físico e social. As demais 54 atividades podem desenvolver somente capacidades linguísticodiscursivas, visto que elas não exigem mais do que reconhecer as informações presentes no texto e sobre o vocabulário.

Lourenço e Cantarotti (2011), por sua vez, tiveram o objetivo de proporcionar aos professores de tradução no curso de Secretariado Executivo uma visão mais ampla acerca da abordagem de ensino nessa área, apresentando primeiramente teorias e procedimentos acerca da atividade tradutória e, em seguida, propondo-se uma sequência didática tendo como gênero utilizado para a prática da tradução os contratos empresariais. O estudo concluiu que essa prática contribui para uma sólida formação do secretário executivo, especificamente, em línguas estrangeiras e tradução.

Também no contexto da tradução, Medeiros (2011) teve o propósito de identificar quais eram os gêneros textuais mais traduzidos por profissionais de Secretariado Executivo da região de Criciúma, Santa Catarina. A partir dos dados coletados e das análises realizadas, a autora chegou à conclusão de que a tradução permeia mais as atividades dos sujeitos envolvidos do que a versão, o gênero e-mail é o mais traduzido e o assunto mais recorrente é sobre viagens.

Revista Expectativa, Toledo/PR, v.20, n. 2, p. 67-89, abr./jun., 2021. 
Em outro estudo, Lugli (2013) procurou demonstrar a necessidade da inserção de gêneros textuais do âmbito internacional nas aulas de espanhol dos cursos de Secretariado Executivo (notadamente sobre exportação/importação). Como conclusão, foi possível constatar que se trabalhou mais as capacidades de ação e linguístico-discursivas, isso porque as capacidades de ação são essenciais para este profissional, uma vez que necessita conhecer aspectos relacionados com o mundo físico, social e subjetivo do gênero de texto por meio do qual realiza as negociações. Além disso, este profissional não pode prescindir das capacidades linguístico-discursivas para poder ler e completar os formulários. No que diz respeito às capacidades discursivas, estas quase não foram trabalhadas porque a organização estrutural do formulário já vem padronizada e, portanto, não há como o profissional usar uma estrutura diferente da já padronizada.

Santos (2014) apresentou uma proposta de trabalho para o ensino de Língua Inglesa para propósitos específicos baseada na abordagem dos gêneros textuais, a ser desenvolvida no curso de Secretariado Executivo Trilíngue de uma instituição privada. De modo conclusivo, a investigação demonstrou que há a existência de uma estrutura de caráter geral, que viabiliza o desenvolvimento produtivo de uma ementa e atividades voltadas para o English for Specific Purposes (ESP), tendo como base os seguintes pontos: 1. diagnóstico das estruturas linguísticas utilizadas pelos alunos (gêneros e sua estrutura); 2. estabelecimento de estratégias para apresentação desses gêneros como prática discursiva (áreas de produção textual e leitura); 3. avaliação da produção textual sob o ponto de vista do docente e do aluno.

No artigo de Lugli (2016), analisou-se dados sobre o comportamento das preposições de, en, $a$, no gênero Ata, redigido em língua espanhola, tentando situá-las de acordo com os sentidos de base (origem, meta e conteúdo) e eixos espaciais (horizontal e continente/conteúdo) propostos por Castilho (2004). O estudo concluiu que os eixos espaciais propostos por Castilho (2004) podem ser aplicáveis ao espanhol e que a gramática utilizada contempla parcialmente os valores preposicionais expressos pelo gênero Ata.

Na tese de doutorado de Lugli (2017), descreveu e analisou os verbos de dizer presentes em 35 atas do Parlamento do Mercosul redigidas em língua espanhola. Como resultado de tal proposta, constatou-se a relevância da descrição e da análise dos verbos de dizer no gênero textual ata, por determinar o teor e as características do gênero, considerado uma prática de referência no ensino de Secretariado Executivo. 
Souza (2018) analisou qual o papel dos gêneros nos materiais didáticos de espanhol para a área de secretariado, especificamente nas obras: El Español por profesiones: secretariado, de Aguirre e Gómez de Enterría (1992); Español para Secretariado, de Durão et al. (1999) e Espanhol para secretariado: um guia prático para secretários, assessores e assistentes, de González (2012). Com base nos resultados coletados, concluiu-se que apenas um dos três materiais investigados estava especificamente direcionado ao ensino de espanhol para fins específicos, nesse caso ao secretariado, a partir da abordagem dos gêneros, da mesma forma que as atividades propostas, embora se trate de uma obra da década de 1990 e não elaborada por secretários.

Reis e Lugli (2019) analisaram o uso da língua espanhola em uma telenovela colombiana no sentido de observar se os enunciados nela presentes reproduzem dizeres estereotipados sobre a profissional de secretariado. A partir dos resultados coletados, arrematou-se que o discurso reproduzido pela telenovela reforça dizeres estereotipados relacionados à secretária, por disseminar ideias que descrevem a profissional como uma mulher que para exercer a profissão precisa apenas possuir beleza física.

Guiando-se por um caminho teórico menos conhecido, Bernardon (2019) descreveu duas atividades de um livro didático de inglês para negócios, a partir dos estudos sobre os gêneros da linguagem e da gramática do design visual (GDV). Como resultados, a autora concluiu que as atividades estão relacionadas à comunicação, ações ecologicamente corretas, tecnologias avançadas, uso de documentos utilizados em setores administrativos e de uso pessoal. Ações que se referiram ao uso de computadores aparecem na segunda atividade, utilizando-se imagens como forma colaborativa para o aprendizado do idioma estrangeiro. Os temas e atividades contribuem para a formação do SE, a partir do ensino de uma língua estrangeira, preparando-os para o exercício dessa profissão.

Por fim, Lugli (2020) se apoia na concepção de que gêneros textuais traduzidos são considerados produtos sociais fundamentais para o ensino de tradução, dado que é por meio desses modelos textuais, elaborados sócio-historicamente, que se torna possível prever comportamentos estruturais e léxico-verbais dos elementos constitutivos do texto, para demonstrar a função dos verbos de dizer no gênero procuração como forma de repensá-los no ensino de espanhol. Como resultados, descobriu-se que os verbos de dizer no gênero 
apresentam valor testemunhal e os modais são utilizados como verbos com função reguladora no registro documental.

A seguir, dedica-se espaço aos procedimentos metodológicos pensados para este trabalho.

\section{PROCEDIMENTOS METODOLÓGICOS}

Neste tópico, dedica-se alguns parágrafos para apresentar detalhadamente os caminhos percorridos para a estruturação desta pesquisa.

Inicialmente, tem-se que ela é de natureza exploratória no tocante aos objetivos e fins, pois procura respostas para um tema que parece ser pouco estudado no secretariado, qual seja: os gêneros textuais/discursivos. Para Gil (2008), a pesquisa exploratória é aquela que procura proporcionar maior familiaridade com o problema (explicitá-lo). Pode envolver levantamento bibliográfico, entrevistas com pessoas experientes no problema pesquisado. Muitas das vezes, assume a forma de pesquisa bibliográfica e estudo de caso.

$\mathrm{Na}$ abordagem do problema, o estudo é qualitativo, já que busca analisar os dados a partir de um viés interpretativo e baseado nos referenciais teóricos, sem se prender às informações quantitativas e /ou estatísticas. Na visão de Minayo (2001, p. 14), essa abordagem "trabalha com o universo de significados, motivos, aspirações, crenças, valores e atitudes, o que corresponde a um espaço mais profundo das relações, dos processos e dos fenômenos que não podem ser reduzidos à operacionalização de variáveis".

Em complemento, no que diz respeito às técnicas, a investigação é bibliográfica e de levantamento de campo. No primeiro caso, lança-se mão de livros, teses, dissertações, artigos, TCCs, dentre outros, para a construção do referencial teórico. Depois, buscam-se mais informações para enriquecer o estudo em uma pesquisa de campo com profissionais da área secretarial.

Para a coleta de dados, elaborou-se um formulário, no Google Docs, precedido de um Termo de Consentimento Livre e Esclarecido (TCLE), que ficou disponível para preenchimento no período de 5/7/2019 a 10/8/2019. Por não estar vinculada a nenhuma universidade, esta pesquisa não teve como ser intermediada por um Comitê de Ética. O link para participação na pesquisa foi divulgado em redes sociais como LinkedIn e Facebook. Ele poderia ser respondido

Revista Expectativa, Toledo/PR, v.20, n. 2, p. 67-89, abr./jun., 2021. 
por profissionais de secretariado (secretários técnicos e executivos, assessores e assistentes), de todas as regiões do Brasil. Ao todo, participaram da pesquisa 16 profissionais.

A estrutura do questionário era a seguinte: Parte 1 - Identificação: sexo, escolaridade, natureza da empresa em que trabalha, tempo de atuação na área de secretariado/assessoria e domínio de línguas estrangeiras (proficiência). Parte 2 - O trabalho com os gêneros textuais/discursivos: conhecimento do que seja gêneros textuais/discursivos, definição do conceito de gêneros textuais/discursivos, causas do desconhecimento, justificativas para uma maior abordagem de gêneros textuais/discursivos de língua materna e menor no de línguas estrangeiras, demandada de atuação com gêneros textuais/discursivos de língua estrangeira, gêneros mais demandados, línguas estrangeiras mais demandadas e percepção dos participantes sobre as contribuições dos estudos sobre gêneros textuais/discursivos para a prática profissional do secretário.

A interpretação dos dados obtidos se deu por meio da técnica Análise de Conteúdo, proposta por Bardin (2011), e que se estruturou em duas fases: $1^{\text {a }}$ - Pré-análise, na qual se estabeleceu um contato inicial com as informações colhidas através dos questionários; na $2^{\mathrm{a}}$, Exploração dos resultados, buscou-se analisá-los extraindo os pontos de vista similares, complementares e antagônicos das respostas, além de confrontá-los com as teorias presentes no referencial teórico da pesquisa aqui empreendida.

Para manter e assegurar o anonimato dos participantes, suas respostas serão identificadas, nos resultados e discussões, por letras e números, sendo: "P" para "Participante"; e 1 a 16 - número de respondentes. Exemplo: P1 - participante 1, P2 - participante 2, P3 participante 3 , etc.

No tópico seguinte, apresentam-se os resultados e sua análise.

\section{APRESENTAÇÃO E ANÁLISE DOS RESULTADOS}

\subsection{IDENTIFICAÇÃO DOS PARTICIPANTES}

Conforme informado nos aspectos metodológicos, a primeira parte do questionário buscou encontrar dados de identificação do público-alvo, quais sejam: secretários técnicos e executivos, assistentes e assessores.

Revista Expectativa, Toledo/PR, v.20, n. 2, p. 67-89, abr./jun., 2021. 
No tocante ao sexo dos participantes, foi possível identificar que $87,5 \%$ deles são do feminino e $12,5 \%$ do masculino. Esses primeiros dados coletados não apresentam nenhuma informação nova, já que no campo secretarial, desde a Segunda Guerra Mundial, a profissão tornou-se majoritariamente de mulheres. Então, é natural que, na aplicação de tais questionários, uma maior parcela de pesquisados seja do sexo feminino.

A segunda informação colhida dos participantes dizia respeito à escolaridade. Para esse dado, os resultados foram os seguintes.

Gráfico 1 - Escolaridade

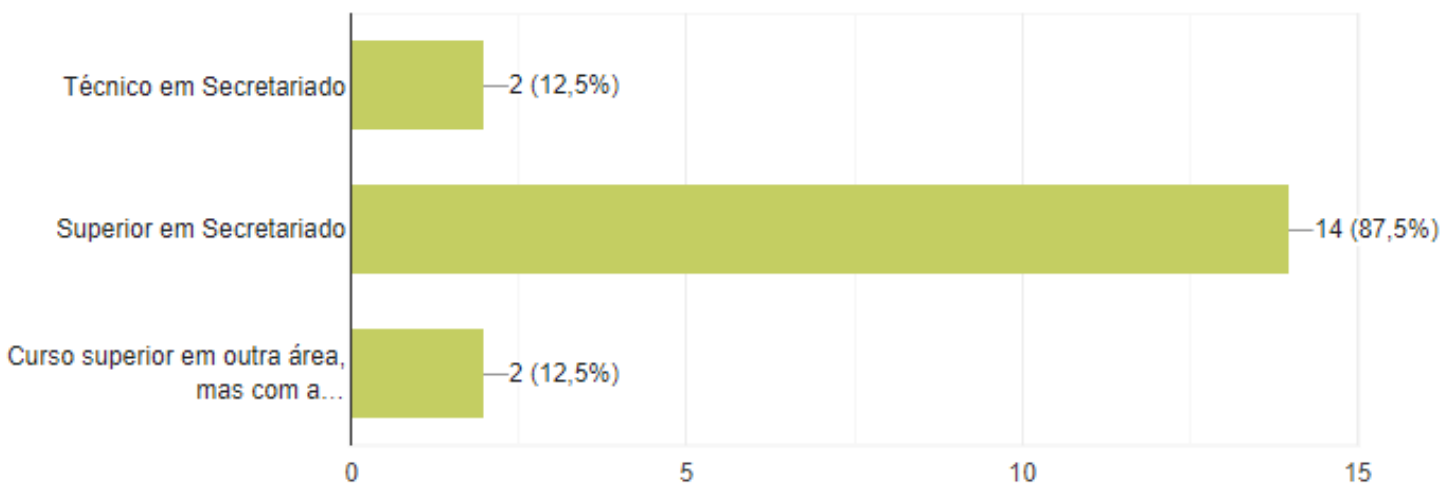

Legenda: Curso superior em outra área, mas com atuação na área de secretariado e assessoria.

Fonte: Elaborado pelos autores com base nos dados coletados (2019).

A partir do gráfico apresentado, é possível notar que 12,5\% dos participantes são Técnicos em Secretariado, 87,5\% possuem curso superior em secretariado e outros 12,5\% cursos superiores em outras áreas, mas com atuação no secretariado.

Nesse sentido, alguns aspectos parecem ser importantes de esclarecer: a formação continuada no secretariado e a formação em outra área, mas atuação no campo secretarial. Assim sendo, dois dos participantes, após concluírem o técnico em secretariado, seguiram para a formação superior na área (o que pode revelar interesse pela carreira e ampliação dos conhecimentos obtidos durante a formação de nível médio). Outro dado relevante diz respeito à formação em outra área, mas a atuação em secretariado. É sabido que, desde sua regulamentação, ou seja, 1985, o campo secretarial tem sido palco da atuação de profissionais formados em outras áreas, tais como: Letras, Direito, Contabilidade, Recursos Humanos, Psicologia, Matemática, História etc. (LAWDER; WILLERS, 2012; TERRA; UCHIMURA; SCOPINHO, 2012).

Revista Expectativa, Toledo/PR, v.20, n. 2, p. 67-89, abr./jun., 2021. 
Além disso, com esse questionamento sobre a escolaridade, e relacionando-o com os gêneros textuais/discursivos de língua estrangeira, pode-se perguntar se uma formação específica na área abriria precedentes para um maior ou menor nível de conhecimento sobre os gêneros. Com base nos resultados deste estudo, isso não foi confirmado.

Seguindo com a apresentação dos resultados encontrados, o próximo diz respeito à natureza da empresa que esses profissionais trabalham.

Gráfico 2 - Natureza da empresa em que trabalha

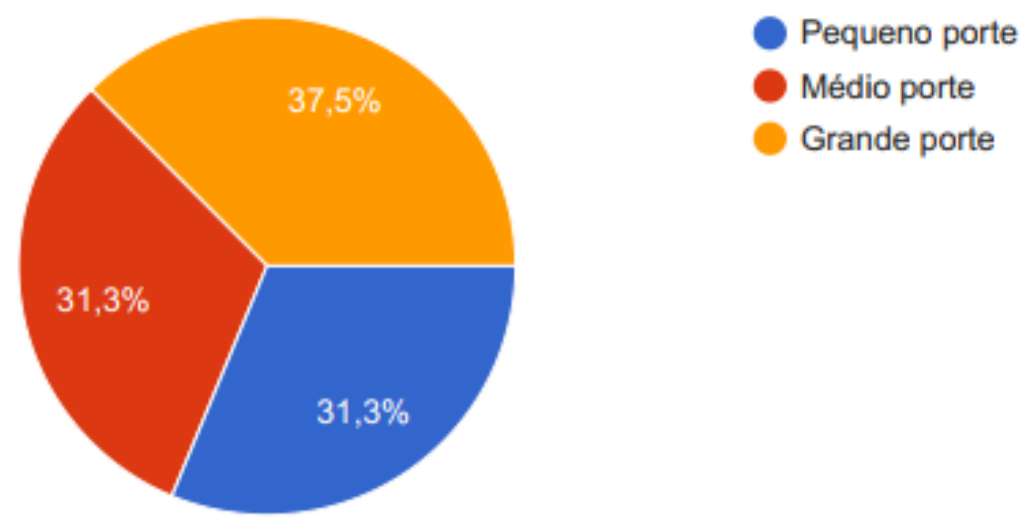

Fonte: Elaborado pelos autores com base nos dados coletados (2019).

Os dados do Gráfico 2 revelam que 37,5\% dos participantes trabalham em empresa de grande ponte, logo, pode-se inferir que eles estão em maior contato com as línguas estrangeiras. Dos demais, $31,3 \%$ estão em empresas de médio e pequeno porte, respectivamente.

A atuação em empresa de grande porte pode influenciar num maior ou menor contato com gêneros textuais/discursivos de língua estrangeira? O questionamento explorado no Gráfico 2 parece ser pertinente à medida que se pensa nos relacionamentos multiculturais dessas organizações, motivados, principalmente, pela globalização e necessidade de negociar com os diferentes países do globo.

A seguir, apresentam-se os resultados encontrados para um questionamento sobre o tempo de atuação na área de secretariado/assessoria. Igualmente como pensado sobre o porte da empresa, questionar o tempo de atuação na área secretarial também pode ser importante para descobrir se há influência no maior ou menor conhecimento/contato dos/com gêneros textuais/discursivos de língua estrangeira.

Revista Expectativa, Toledo/PR, v.20, n. 2, p. 67-89, abr./jun., 2021. 
Gráfico 3 - Tempo de atuação na área de secretariado/assessoria

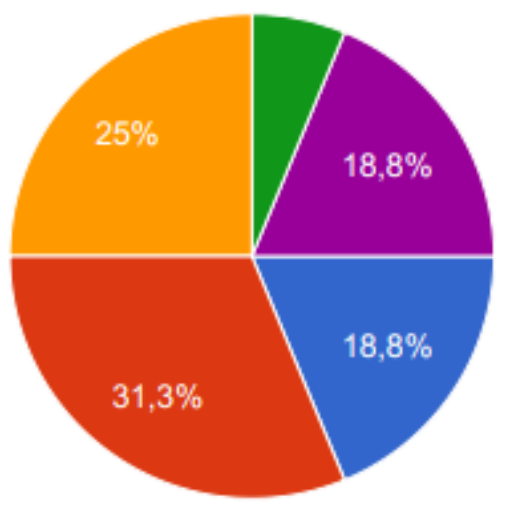

Até 1 ano

De 1 a 4 anos

De 4 a 7 anos

De 7 a 10 anos

Mais de 10 anos

Fonte: Elaborado pelos autores com base nos dados coletados (2019).

As informações colhidas para o questionamento anterior mostram que 31,3\% dos profissionais investigados estão na área de secretariado/assessoria num período de 1 a 4 anos, quer dizer, representam um grupo de trabalhadores recém-chegados; 25\% estão de 4 a 7 anos; 18,8\% até 1 ano, bem como há mais de 10 anos, respectivamente; e, por fim, 6,3\% de 7 a 10 anos.

Com base nesses resultados, não é possível fazer qualquer afirmativa sobre um possível maior conhecimento/envolvimento dos profissionais pesquisados com os gêneros textuais/discursivos de língua estrangeira, a partir dos anos de atuação na área, haja vista que a maior parte dos participantes está no secretariado há, no máximo, 4 anos $(31,3 \%)$.

O próximo gráfico diz respeito à proficiência em línguas estrangeiras.

Gráfico 4 - Proficiência em línguas estrangeiras

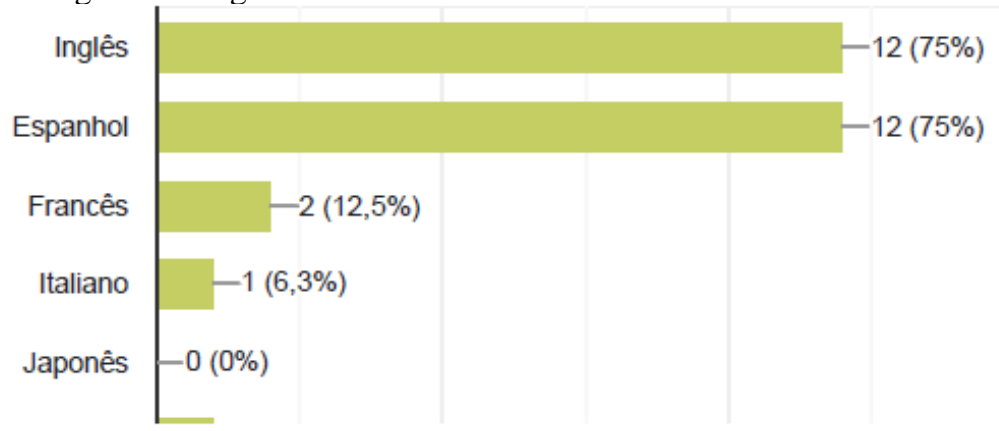

Fonte: Elaborado pelos autores com base nos dados coletados (2019).

A partir da leitura do gráfico anterior, é possível afirmar que a maior parte dos participantes possui proficiência nas línguas inglesa e espanhola, $75 \%$, respectivamente. Em

Revista Expectativa, Toledo/PR, v.20, n. 2, p. 67-89, abr./jun., 2021. 
seguida, aparece o francês, $12,5 \%$; e o italiano, $6,3 \%$. Sobre esse resultado, podemos relacionálo com a oferta das disciplinas de língua estrangeira pelos cursos de secretariado no Brasil (a maioria oferece apenas inglês; alguns, inglês e espanhol; e outros inglês, espanhol e francês). Além disso, também vale lembrar dos perfis das vagas oferecidas pelo mercado de trabalho brasileiro, que pedem, quase que com em exclusividade, domínio do inglês. Em outras vagas, no entanto, aparecem inglês e espanhol.

Um aspecto que não foi explorado no questionário desta pesquisa, mas que pode estar em estudos futuros é averiguar como a proficiência desses profissionais foi obtida. Se com base no Quadro Europeu Comum de Referência para as línguas (QECR), se por meio de certificados diversos etc.

Assim sendo, conclui-se a primeira parte da apresentação dos resultados (Identificação do público pesquisado) e começa-se a segunda ( $\mathrm{O}$ trabalho com os gêneros textuais/discursivos).

\subsection{OS GÊNEROS TEXTUAIS/DISCURSIVOS NA PERSPECTIVA DOS PARTICIPANTES}

O primeiro questionamento dessa segunda parte foi: Você sabe o que são gêneros textuais/discursivos? Do total de pesquisados, 16, 62,5\% disseram que "sim" e 37,5\% que "não".

Aos que responderam positivamente, foi solicitado que explicassem, com suas palavras, o que seriam esses gêneros textuais/discursivos. As dez respostas coletadas são expostas a seguir.

Gênero textual é a maneira escolhida para descrever um fato, história que pode ser formal/informal, dependendo muito do contexto empregado. No caso do gênero discursivo, que está presente em quase todas as ocasiões, como em uma receita, uma mensagem de e-mail e até a certidão de nascimento, podemos afirmar que o gênero textual discursivo é reflexo da estrutura social da atualidade. (P1)

Cartas, E-mails, onde precisamos argumentar sobre determinado assunto. (P2)

Tipos de texto, processos de produção, organização de discurso e principalmente a enunciação para expressar uma mensagem. (P3)

Estilo textual assumido para redação de um texto (P6)

Revista Expectativa, Toledo/PR, v.20, n. 2, p. 67-89, abr./jun., 2021. 
É o uso dos textos no nosso cotidiano. (P8)

São gêneros que usamos para comunicar como cartas e-mail mensagem de WhatsApp uma receita etc. (P9)

São tipos textuais, como: narração, dissertação/argumentação. Cada um com a sua estrutura e/ ou o que compõe ela, ou seja, sua maneira de ser escrito os padrões do gênero. (P10)

Cada texto possui uma estrutura e linguagem, como por exemplo os textos discursivos, narrativos, etc. (P11)

Textos utilizados para enunciar algum assunto/realizar uma comunicação (P14)

Tipos de documentos textuais com determinadas características. (P16)

Com base nas respostas anteriores, embora os participantes não demonstrem uma clareza conceitual do assunto, há noções bastante significativas do que seriam os gêneros textuais/discursivos, como nas respostas de P1, P2, P8, P9, P14 e P16, indo ao encontro do que postulam autores como Bazerman (2011) e Marcuschi (2011) - a deia de que gêneros são mecanismos comunicacionais e que fazemos uso deles sempre que precisamos estabelecer interações com outros membros da comunidade. No entanto, há certa confusão conceitual em P3, P6, P10 e P11, como já adiantado em Bezerra (2017) quando fala dos equívocos cometidos por usuários da língua na tentativa de estabelecer relação entre gênero, texto e discurso. Especificamente, na falta de clareza teórica sobre gênero e texto, gênero e suporte, gênero e domínio discursivo, gênero e forma/estrutura e gênero e tipo textual.

Se o participante respondeu "não" à questão anterior, ele poderia justificar tal desconhecimento. Eis as 4 respostas colhidas (P5 e P13 não responderam):

\footnotetext{
Não recordo do que se trata, mas acredito que já estudei algo básico. (P4)

Nunca ouvi falar deste tema. (P7)

Nunca ouvi falar. (P12)
}

Não entendo a diferença entre gêneros e textos literários claramente! Tudo me confunde: propaganda e etc. (P15)

Ao passo que alguns participantes demonstraram certo conhecimento sobre o assunto em pauta, outros parecem desconhecer totalmente do que se trata. Sobre isso, parece interessante mencionar que os participantes P4 e P12 possuem formação superior em secretariado, P7 em outra área e P15 possui o técnico e superior em secretariado. Sabendo que

Revista Expectativa, Toledo/PR, v.20, n. 2, p. 67-89, abr./jun., 2021. 
os cursos de secretariado oferecem disciplinas de língua materna e estrangeira(s), julga-se desconfortante os egressos não saberem do que se trata. Nesse sentido, também há de se considerar a possibilidade de que os docentes de língua(s) não tenham ministrado tais conteúdos para as turmas.

Uma vez que alguns participantes desconhecem o que sejam os gêneros textuais/discursivos, fica difícil para eles reconhecê-los no ambiente de trabalho. Logo, a pesquisa aqui empreendida apresenta essa lacuna no tocante a representatividade das respostas colhidas.

Nos cursos de formação em secretariado (nível médio e superior), nota-se alguma abordagem na sala de aula sobre os gêneros textuais/discursivos de língua materna, mas pouco se explora os de língua estrangeira (SOUZA, 2018). Tendo em vista isso, procurou-se saber dos participantes a que fator/fatores eles atribuem essa ausência. Entre as dezesseis respostas recebidas, resolveu-se apresentar as mais significativas, haja vista que alguns participantes acabaram fugindo do tema e outros colocaram informações imprecisas:

À falta de conhecimento básico sobre o idioma e o professor acaba precisando fazer esse resgate. (P2)

Atribuo ao fato de que a maioria dos alunos que ingressam em Secretariado necessitam de um trabalho em língua estrangeira focado em formação básica de proficiência ou instrumental. [...]. (P6)

[...] poucas pessoas têm fluência de 1 segundo idioma, isso também dificulta. (P8)

Os alunos não terem base nas línguas estrangeiras, às vezes nem na materna. (P11)

Falta de proficiência dos alunos. O curso precisa abordar o básico para iniciar o estudante no idioma, porque a base escolar não permite que cheguemos ao ensino médio com o inglês nem mesmo intermediário. (P13)

Dificuldade em apresentar os textos pela não homogeneidade de conhecimento de língua estrangeira pelos discentes. (P14)

Parece que a principal justificativa para a ausência da exploração dos gêneros textuais/discursivos nos cursos técnicos e superiores de secretariado seja a falta de conhecimento dos alunos sobre as línguas estrangeiras (advinda possivelmente do ensino médio), haja vista que o professor precisa "começar do zero" e não resta tempo hábil para aprofundamento dos gêneros na sala de aula. Tal posicionamento está presente nas respostas dos participantes que responderam à questão proposta: “[...] falta de conhecimento básico sobre

Revista Expectativa, Toledo/PR, v.20, n. 2, p. 67-89, abr./jun., 2021. 
o idioma [...]” (P2); “[...] a maioria dos alunos que ingressam em Secretariado necessitam de um trabalho em língua estrangeira focado em formação básica [...]” (P6); “[...] poucas pessoas têm fluência de 1 segundo idioma [...]” (P8); “Os alunos não terem base nas línguas estrangeiras [...]" (P11); "Falta de proficiência dos alunos." (P13); "Dificuldade em apresentar os textos pela não homogeneidade de conhecimento de língua estrangeira [...]” (P14).

Além disso, pode-se mencionar a falta de material didático de língua estrangeira com abordagem atual em gêneros textuais/discursivos e a pequena presença de professoressecretários de línguas estrangeiras nos cursos técnicos e superiores de secretariado (SOUZA, 2018). Sobre esse aspecto, convém mencionar que tais professores-secretários precisam ter formação na área de Licenciatura em Letras e Mestrado/Doutorado na área da Linguagem, haja vista que só a graduação em Secretariado não é suficiente para garantir um eficiente e eficaz ensino de língua estrangeira.

Em seguida, procurou-se saber dos participantes se, no trabalho diário como secretário, assessor ou assistente, era demandado deles uma atuação com gêneros textuais/discursivos de língua estrangeira. Dos dezesseis participantes da pesquisa, $87,5 \%$ deles não recebem qualquer demanda de gêneros nos diferentes idiomas, ao passo que para 12,5\%, há solicitações dessa natureza no espaço laboral. Considerando que há uma parcela de participantes que nem sabe o que seja os gêneros textuais/discursivos, as respostas para esse questionamento talvez tivessem um percentual positivo para as demandas em língua estrangeira.

Para aqueles que responderam "sim”, buscou-se conhecer quais eram os gêneros de língua estrangeira mais demandados e as respostas encontradas foram:

$$
\begin{aligned}
& \text { Explanation, Information Report, Procedure. (P1) } \\
& \text { Ofícios, documentos jurídicos e relatórios. (P2) }
\end{aligned}
$$

Inicialmente, pode-se perguntar se explanation e procedure são gêneros textuais/discursivos. Talvez tenha faltado detalhes na resposta de P1, de modo que deixasse claro o que queria dizer. Além disso, por que somente os "gêneros" de P1 estão em inglês e os de P2 estão em português? No comando da questão não foi solicitado que o respondente escrevesse em língua estrangeira.

Revista Expectativa, Toledo/PR, v.20, n. 2, p. 67-89, abr./jun., 2021. 
Ainda sobre o universo das línguas estrangeiras no ambiente de trabalho, procurou-se saber dos participantes qual(is) língua(s) estrangeira(s) eles se relacionavam nos escritórios. As respostas mais recorrentes foram: Inglês (P1, P2, P3, P5, P6, P7 e P8), Espanhol (P3, P6 e P9), Francês (P6) e Italiano (P7). Desse modo, tem-se que P3 se relaciona com duas línguas, inglês e espanhol; P6 com três, inglês, espanhol e francês; e P7 com outras duas inglês e italiano.

Mesmo que alguns pesquisados (P4, P7, P12 e P15) não saibam do que se trata, não conhecem ou não conseguem diferenciar gêneros textuais/discursivos de textos literários, objetivou-se saber dos participantes, a partir de sua relação cotidiana com os gêneros textuais/discursivos de língua estrangeira no trabalho, quais seriam as contribuições dos estudos deles para a prática profissional do secretário?

\footnotetext{
Adaptativa para situações institucionais adversas, bem como interpretação ideal da mensagem transmitida. (P6)

O aprendizado do idioma seria mais veloz. (P8)

Quanto mais conhecimento deles mais fácil se dará na prática profissional quando ocorrer oportunidade. (P9)

Leitura e prática de escrita na língua que se pretende escrever. (P11)

Melhor exploração e análise dos textos e documentos em língua estrangeira durante a formação. Apresentação mais ampla de textos que abordem os mais distintos gêneros textuais. (P14)
}

Tornaria o profissional mais bem preparado para atuar na área. (P16)

De modo geral, reconhece-se que as respostas sobre as contribuições dos gêneros para a prática profissional são sucintas, haja vista que cinco dos seis respondentes mal conseguiram elaborar duas frases replicando tal questionamento. Isso talvez se justifique pela falta de conhecimento conceitual dos participantes quanto aos gêneros textuais/discursivos.

Nas palavras de Bezerra (2017), a prática com os gêneros textuais/discursivos possibilita ao interlocutor ampliar seu horizonte sobre a função do texto e do discurso nas relações sociais. Desse modo, o indivíduo consegue melhorar sua desenvoltura em situações adversas, compreensão real das mensagens transmitias por outros colaboradores e, inclusive, no aprendizado de um novo idioma, conforme destacado por P6 e P8, respectivamente: "Adaptativa para situações institucionais adversas, bem como interpretação ideal da mensagem transmitida."; “O aprendizado do idioma seria mais veloz.”. Portanto, no dia a dia do secretário,

Revista Expectativa, Toledo/PR, v.20, n. 2, p. 67-89, abr./jun., 2021. 
conhecer os diferentes gêneros textuais/discursivos que circulam no ambiente organizacional pode ser relevante para o estabelecimento de relações empresariais efetivas em termos comunicacionais. Em suma, a contribuição dos gêneros textuais/discursivos de língua estrangeira para o secretariado é vista como algo positivo e que, se bem explorado, pode ajudar o trabalhador em sua prática.

Nesse entendimento, Marcuschi (2011, p. 159) destaca que os gêneros são "entidades dinâmicas, históricas, sociais, situadas, comunicativas, orientadas para fins específicos, ligadas a determinadas comunidades discursivas, ligadas a domínios discursivos, recorrentes e estabilizadas em formatos mais ou menos claros". Assim sendo, alguns dos participantes da pesquisa reconhecem que o seu conhecimento deixaria os profissionais da área preparados para enfrentar os contratempos no dia a dia laboral. Sobre esse aspecto, P14 destaca: "Melhor exploração e análise dos textos e documentos em língua estrangeira durante a formação. Apresentação mais ampla de textos que abordem os mais distintos gêneros textuais".

Ao passo que seis participantes responderam de forma mais ou menos pontual o questionamento sobre as contribuições dos gêneros textuais/discursivos de língua estrangeira, outros não apresentam consistência na formulação do conteúdo.

\footnotetext{
De grande importância. O profissional de secretariado é um profissional que precisa ter propriedade sobre tudo o que fala e dominar um assunto, o destaca, frente profissionais medianos ou pouco interessados na carreira. (P1)

O docente deve ter conhecimento do dia a dia e do tipo de comunicação usada na área de secretariado. (P3)
}

Em P1, há certa confusão sobre o falar e escrever na área de secretariado. Logo, não é possível compreender a relação que o participante pretendeu estabelecer ao destacar a fala e dominar o assunto. Já em P3, o respondente esclarece que o docente deve conhecer o dia a dia e o tipo de comunicação usada no campo secretarial, mas o enunciado da questão quer saber as contribuições do estudo dos gêneros textuais/discursivos para a área de secretariado. Sendo assim, também não é possível decifrar o que ele quis dizer com tal resposta.

A seguir, tem-se às considerações finais do estudo. 


\section{CONSIDERAÇÕES FINAIS}

Neste trabalho, objetivou-se conhecer a compreensão dos profissionais de secretariado sobre os gêneros textuais/discursivos. Para tanto, elencou-se os seguintes objetivos específicos: a) descobrir se os profissionais da área sabem o que são os gêneros textuais/discursivos; b) identificar, no que tange aos que conhecem o que são, como eles materializam esse conceito de gênero textual/discursivo; c) verificar se, no trabalho diário como secretário, assessor ou assistente, é demandada atuação com gêneros textuais/discursivos de língua estrangeira; e d) entender quais seriam as contribuições dos gêneros textuais/discursivos de língua estrangeira para a área de secretariado a partir do ponto desses trabalhadores.

Após tabulação dos dados coletados e apresentação na parte dos resultados e discussão da pesquisa, descobriu-se que os profissionais da área sabem parcialmente o que são os gêneros textuais/discursivos. Ademais, os que conhecem não sabem como esses gêneros se materializam na prática laboral. Também não foi possível ter certeza se no dia a dia secretarial é demandada atuação com diferentes gêneros textuais/discursivos de língua estrangeira. Finalmente, a contribuição dos gêneros textuais/discursivos de língua estrangeira para o secretariado é vista como algo que pode ajudar no trabalho secretarial, mas não há outras informações sobre como eles podem contribuir de fato com a prática da profissão.

Posto isso, pensa-se que seria interesse desenvolver novos estudos para investigar, por exemplo: a compreensão dos participantes e as contribuições dos gêneros textuais/discursivos de língua estrangeira em uma amostra maior de secretários, assistentes e assessores, haja vista que neste trabalho só foram ouvidos dezesseis profissionais. Além disso, também seria interesse conhecer qual a percepção dos professores de línguas sobre a contribuição dos gêneros textuais/discursivos para a prática laboral do secretário.

\section{REFERENCIAS}

AGUIRRE, B.; GÓMEZ DE ENTERRÍA, J. EI Español por profesiones: Secretariado. Madrid: SGEL, 1992.

ARAÚJO, A. D. Lexical signalling: a study of unspecific nouns in book reviews. 1996. 284

f. Tese (Doutorado em Letras) - Universidade Federal de Santa Catarina, Florianópolis, 1996.

Bardin, L. Análise de conteúdo. São Paulo: Edições 70, 2011. 
BAZERMAN, C. Gênero, Agência e Escrita. In: HOFFNAGEL, J. C.; DIONÍSIO, A. P. (Orgs.). Tradução de Judith Chambliss Hoffnagel. 2. ed. São Paulo: Cortez, 2011.

BERNARDON, M. Gêneros da linguagem e multimodalidade em livros de inglês para negócios. In: ENCONTRO NACIONAL ACADÊMICO DE SECRETARIADO EXECUTIVO, 6., 2019, Viçosa. Anais [...] Viçosa: UFV/ABPSEC, 2019.

BEZERRA, B. G. Gêneros no contexto brasileiro: questões (meta)teóricas e conceituais. São Paulo: Parábola Editorial, 2017.

BIASI-RODRIGUES, B. Estratégias de condução de informações em resumos de dissertações. 1998. 307 f. Tese (Doutorado) - Universidade Federal de Santa Catarina, Florianópolis, 1998.

CASTILHO, A. T. Diacronia das preposições do eixo transversal no Português brasileiro. In: NEGRI, M. J. F.; OLIVEIRA, R. P. (Orgs.). Sentido e significação: em torno da obra de Rodolfo Ilari. São Paulo: Contexto, 2004.

DURÃO, A. B. A. B. (Org.). Español para secretariado. Londrina: Editora da UEL, 1999.

GIL, A. C. Como elaborar projetos de pesquisa. 4. ed. São Paulo: Atlas, 2008.

GONZÁLEZ, P. V. Espanhol para secretariado: um guia prático para secretários, assessores e assistentes. Rio de Janeiro: ELSEVIER, 2012.

LAWDER, V. G. B.; WILLERS, E. M. Atuação do bacharel em secretariado executivo em cargos com atribuições privativas a sua categoria profissional: estudo em uma empresa de grande porte do oeste do Paraná. Revista Expectativa, v. 11, n. 1, p. 41-58, nov. 2012.

LOURENÇO, F. M. A.; CANTAROTTI, A. Tradução - abordagem de ensino/aprendizagem para o secretariado executivo: o gênero "versão de contratos". In: ENCONTRO NACIONAL ACADÊMICO DE SECRETARIADO EXECUTIVO, 2., 2011, Passo Fundo. Anais [...] Passo Fundo: Universidade de Passo Fundo, 2011.

LUGLI, V. C. P. Géneros textuales: análisis de una unidad didáctica de español para fines específicos. In: SEMINÁRIO DO CENTRO DE ESTUDOS LINGUÍSTICOS E LITERÁRIOS DO PARANÁ, 20., 2011, Londrina. Anais [...] Londrina: Universidade Estadual de Londrina, 2011.

LUGLI, V. C. P. Géneros de la comunicación internacional en cursos de secretariado ejecutivo. R.G.Secr., GESEC, São Paulo, v. 4, n. 2, p. 73-89, jul.-dez., 2013.

LUGLI, V. C. P. O gênero ata e as preposições: reflexões para o ensino de espanhol para secretariado. R.G.Secr., GESEC, São Paulo, v. 7, n. 3, p. 172-201, set.-dez., 2016. 
LUGLI, V. C. P. Verbos de dizer em língua espanhola: uma análise funcionalista em atas do parlamento do Mercosul. 2017. 295 f. Tese (Doutorado em Letras) - Universidade Estadual de Maringá, Maringá, 2017.

LUGLI, V. C. P. Um estudo de verbos de dizer e de verbos modais em traduções e versões: contributos ao ensino de espanhol para o profissional de Secretariado Executivo. Revista Expectativa, v. 19, n. 2, p. 92-117, out. 2020.

MARCUSCHI, L. A. Produção textual, análise de gêneros e compreensão. São Paulo: Parábola Editorial, 2008.

MARTINS, C. B.; GENGHINI, L. A.; MACCARI, E. A.; GENGHINI, E. B. Parâmetros para definições de linhas de pesquisas. In: ENCONTRO NACIONAL ACADÊMICO DE SECRETARIADO EXECUTIVO, 2., 2011, Passo Fundo. Anais [...] Passo Fundo: Universidade de Passo Fundo, 2011.

MARTINS, C. B.; LEAL, F. G.; SOUZA, E. C. P.; TODOROV, M. C. A. A busca da cientificidade do secretariado no contexto brasileiro: aspectos históricos e atuais. R. Gest. Anál., Fortaleza, v. 6, n. 1/2, p. 270-286, jan./dez. 2017. Doi:10.12662/2359618xregea.v6i1/2.p270-286.2017

MEDEIROS, A. C. Secretariado executivo e a tradução: identificando os gêneros escritos mais traduzidos na região sul de Santa Catarina. 2011. 47 f. Monografia (Graduação em Secretariado Executivo) - Universidade do Extremo Sul Catarinense, Criciúma, 2011.

MILLER, C. R. Genre as social action. In: FREEDMAN, A.; MEDWAY, P. (Eds.). Genre and the new rhetoric. London: Taylor \& Francis, 1994. p. 23-42. Originalmente publicado em: Quarterly Journal of Speech, v. 70, p. 151-167, 1984.

MINAYO, M. C. S. Ciência, técnica e arte: o desafio da Pesquisa Social. In:

MINAYO, M. C. S. (Org.) Pesquisa social: teoria, método e criatividade. Petrópolis: Vozes, 2001, p. 09-30.

MOTTA-ROTH, D. Rhetorical features and disciplinary cultures: a genre-based study of academic book reviews in linguistics, chemistry, and economics. 1995. $358 \mathrm{f}$. Tese (Doutorado em Letras) - Universidade Federal de Santa Catarina, Florianópolis, 1995.

REIS, K. N. B; LUGLI, V. C. P. Gêneros textuais em língua espanhola: um estudo do gênero textual telenovela e das representações sobre a função secretarial, a partir da teoria de gêneros e da análise crítica do discurso. In: ENCONTRO NACIONAL ACADÊMICO DE SECRETARIADO EXECUTIVO, 6., 2019, Viçosa. Anais [...] Viçosa: UFV/ABPSEC, 2019.

ROJO, R. Gêneros do discurso e gêneros textuais: questões teóricas e aplicadas. In: MEURER, J. L.; BONINI, A.; MOTTA-ROTH, D. Gêneros: teorias, métodos e debates. São Paulo: Parábola Editorial, 2005, p. 184-207. 
SANTOS, F. R. S. ESP e gênero textual: uma proposta de trabalho na área de secretariado. 2014. 105 f. Dissertação (Mestrado em Linguística) - Universidade Cruzeiro do Sul, São Paulo, 2014.

SOUZA, E. C. P. A abordagem comunicativa em materiais didáticos de Espanhol Língua Estrangeira (E/LE) para o curso de Secretariado Executivo. 2015. 60 f. Trabalho de Conclusão de Curso (Graduação em Secretariado Executivo) - Fundação Universidade Federal do Amapá, Macapá, 2015.

SOUZA, E. C. P. Reflexões sobre o ensino de língua para fins específicos a partir da abordagem dos gêneros em manuais e livro didático de espanhol para secretariado. 2018. 114 F. Dissertação (Mestrado em Linguística) - Universidade Cruzeiro do Sul, São Paulo, 2018.

TERRA, E. F.; UCHIMURA, J.; SCOPINHO, R. A. A exposição de estereótipos do secretário executivo veiculados pela mídia. Linguagem Acadêmica, Batatais, v. 2, n. 1, p. 73-91, jan./jun. 2012. 